\title{
Maquete de Máquina de Ensaio Universal: Ferramenta de Ensino Odontológico sob a Óptica de um Aluno de Graduação
}

\author{
Murilo de Almeida Manoel, Dagma Venturini Marques Abramides, Paulo Afonso Silveira \\ Francisconi, Ana Flávia Sanches Borges* \\ Faculdade de Odontologia de Bauru da Universidade de São Paulo \\ * Autora para correspondência: afborges@fob.usp.br
}

\begin{abstract}
RESUMO
Ao iniciar o curso de Odontologia, os alunos se deparam com uma disciplina intitulada Materiais Dentários. Essa disciplina possui dificuldades inerentes ao ensino de partes de seu conteúdo, como as propriedades mecânicas dos materiais odontológicos. Tal fato se deve, provavelmente, à presença de uma linguagem própria e de conceitos mecânicos e físicos que fogem do cotidiano do aluno de graduação de Odontologia; somando-se a isso, temos um meio virtualizado onde esses alunos estão inseridos. Esse conjunto pode trazer dificuldades para a apreensão de conteúdo ao estudante, uma vez que existem diversas maneiras de assimilação de novas informações. $\mathrm{O}$ professor, portanto, deve compreender de onde advém a dificuldade dos alunos em apreender os conteúdos e então traçar estratégias para a melhoria do ensino. Assim, o objetivo do presente trabalho é expor como uma Maquete de Máquina de Ensaio Universal pode tornar inteligíveis conceitos abstratos das propriedades dos materiais dentários, permitindo o aprimoramento da compreensão de tais noções por parte dos alunos de graduação em Odontologia e o aperfeiçoamento do ensino.
\end{abstract}

Palavras-chave: Metodologia; Materiais Dentários; Conhecimento.

\begin{abstract}
In the beginning of the Dentistry course students take a subject called Dental Materials. This subject presents difficulties inherent to the content, like the mechanical properties of dental materials. This is probably due to the presence of a particular vocabulary and of mechanical and physical concepts that are far from the Dentistry student everyday; in addition to that these students are living in a virtual world. This set of characteristics can bring difficulties to student's learning, once there are many ways to take in new information. Thus, the teacher must understand where does the students' learning difficulty come from and create strategies to improve teaching. The purpose of this work is to expose how a Universal Testing Machine Model can make concepts of dental materials properties more intelligible, enhancing Dentistry graduation students' learning, and also improving the teaching.
\end{abstract}

Keywords: Methodology; Dental Materials; Knowledge.

\section{Introdução}

Propriedades mecânicas dos materiais utilizados em Odontologia são um dos assuntos introdutórios da disciplina Materiais Dentários, ministrada no início da graduação em Odontologia. Por vezes esse conteúdo é apresentado de forma teórico-expositiva, algo que dificulta a compreensão do aluno de graduação. Essa dificuldade advém do fato de que dessa maneira o ensino se torna subjetivo e confuso ao aluno.
Segundo Vieira Junior e Colvara (2007), ao ministrarem aulas expositivas os professores não são capazes de manterem seus alunos focados no assunto apresentado. Isso não se deve à capacidade do professor como tal, mas a elementos virtuais que permeiam a vida das pessoas desde crianças, fazendo com que metodologias tradicionais de ensino não se tornem atrativas, e sim maçantes, uma vez que a capacidade de concentração dessas crianças quando jovens/adultos com essas metodologias expositivas torna-se deficiente. 
Isso talvez seja o motivo pelo qual poucos alunos compreendam o conteúdo apresentado. Não tão distantes da realidade de jovens, os conteúdos eram ministrados de maneira verticalizada, em que o professor ensinava expositivamente o conhecimento e o aluno memorizava e repetia conceitos. Esse modelo não é mais recomendado, apesar de largamente usado, devido às evoluções tecnológicas que vivenciamos, as quais geram um ambiente dinâmico e interativo, que, por sua vez, influencia os alunos e por consequência afeta as metodologias de ensino que deverão adequar-se às novas realidades de cada geração (VIEIRA JUNIOR \& COLVARA, 2007).

De acordo com Becker (1994), a aquisição do conhecimento independe da trajetória hereditária e das condições evolutivas, diferentemente do que ditavam pensadores consagrados dos séculos XVIII e XIX para justificar atos de alguns povos. Portanto, o ser humano pode ser definido como um projeto a ser construído. E no atual século XXI o ensino e, consequentemente, a apreensão de conteúdos dependerão de quão interativa e dinâmica for a exposição destes didaticamente. $\mathrm{O}$ professor antes de tudo deve ser um instrumento que transfira o saber ao aluno de modo inteligível. O ideal é que o ensino se dê de maneira horizontalizada entre professor e aluno, tendo apenas o saber em um patamar elevado e não este e o professor ocupando o mesmo, pois assim se alcançará o aprendizado propriamente dito e se formará um ser pensante e questionador, com conceitos teóricos embasados e opiniões consistentes.

Sensitivo: gosta de experimentos, fatos, abstrair pelos sentidos (vendo, ouvindo e etc.) Visual: assimila mais o que veem (figuras, gravuras, filmes)

Ativo: prefere experimentar que observar e refletir

Sequencial: aprende por etapas, de forma linear
Para tanto, o professor deve entender como seus alunos aprendem. O modelo de Felder e Silverman (1988) classifica o aluno entre diversas maneiras pelas quais este aprende. Existem os alunos que assimilam conhecimento por meio da abstração e experimentação, são os sensitivos; os que assimilam pela visão, os visuais; os que efetivamente experimentam e refletem são os ativos; os que precisam da segmentação do assunto seguindo um raciocínio linear são os sequenciais; os que apreciam conceitos, teorias e análise são os intuitivos; os que preferem explicações escritas ou faladas, os verbais; os que gostam de fazer conexões mentais a partir de teorias são os reflexivos; e os que sintetizam conhecimento aprendendo em saltos são os globais (Quadro 1 ).

Analisando essas observações de como os alunos aprendem, e dado o mundo dinâmico em que estão inseridos, é possível que muitos dos estudantes de graduação sejam sensitivos e visuais e, portanto, a visualização dos testes mecânicos, assim como da direção das forças mastigatórias, pode clarear os aspectos difíceis de serem entendidos por parte dos alunos de Odontologia, além de estimulá-los para questões do dia a dia da prática profissional, bem como incentivá-los a darem a devida importância ao conteúdo apresentado pela visualização direta de sua aplicação profissional. A incorporação de uma ferramenta dinâmica e diferenciada no processo de ensino amplia de forma substancial os horizontes perceptivos do aluno quanto aos conteúdos; entretanto, deve vir acompanhada de uma reflexão de ensino e consciência didática na relação professor-aluno-conhecimento (VIEIRA JUNIOR \& COLVARA, 2007).

Intuitivo: gosta de conceitos, teorias, análises e significados

Verbal: prefere explicações escritas ou faladas

Reflexivo: faz ligações teóricas, gostam de pensar

Global: aprende em saltos, sintetizam o conhecimento

Quadro 1 - Resumo do modelo de FELDER e SILVERMAN (1988). 
Nesse sentido, foi desenvolvido um projeto de maquete funcional: contratou-se uma empresa para o desenho e o desenvolvimento do objeto, denominado Simulador Manual de Ensaios Mecânicos Odontológicos (Figura 1), que é um modelo reduzido de máquina de ensaio universal, com o objetivo do aprimoramento do ensino das propriedades mecânicas, com destaque para as dos Materiais Odontológicos. Tal projeto foi custeado com verba Fapesp, número 2011/18061-0. Esse equipamento permite simular ensaios mecânicos que são utilizados em pesquisas que reproduzem as direções das tensões mastigatórias sobre os elementos dentários e restaurações, como teste de compressão (Figura 2), teste de cisalhamento (Figura 3), teste de tração (Figura 4) e teste de flexão em três pontos (Figura 5).

\section{Teste de Compressão}

O processo de mastigação é constituído, dentre as inúmeras forças que o compõem, pelas forças de compressão. Sendo assim, a análise dessa força sobre materiais restauradores, por exemplo o amálgama dentário, resina composta e cimentos, é necessária para se determinar o ponto de falha do material, antes que esse seja posto em função. Nesse teste, há uma complexa interação de forças dissipativas, como as de cisalhamento e de tração, e por esse motivo o corpo de prova deve apresentar o comprimento duas vezes maior que o diâmetro para resultados satisfatórios. Vale ressaltar que esse teste é muito usado para materiais friáveis, os que não sofrem deformação plástica, em comparação com os dúcteis, exatamente por essa complexidade de forças (CRAIG \& POWERS, 2004) (c.f. Tabela 1).

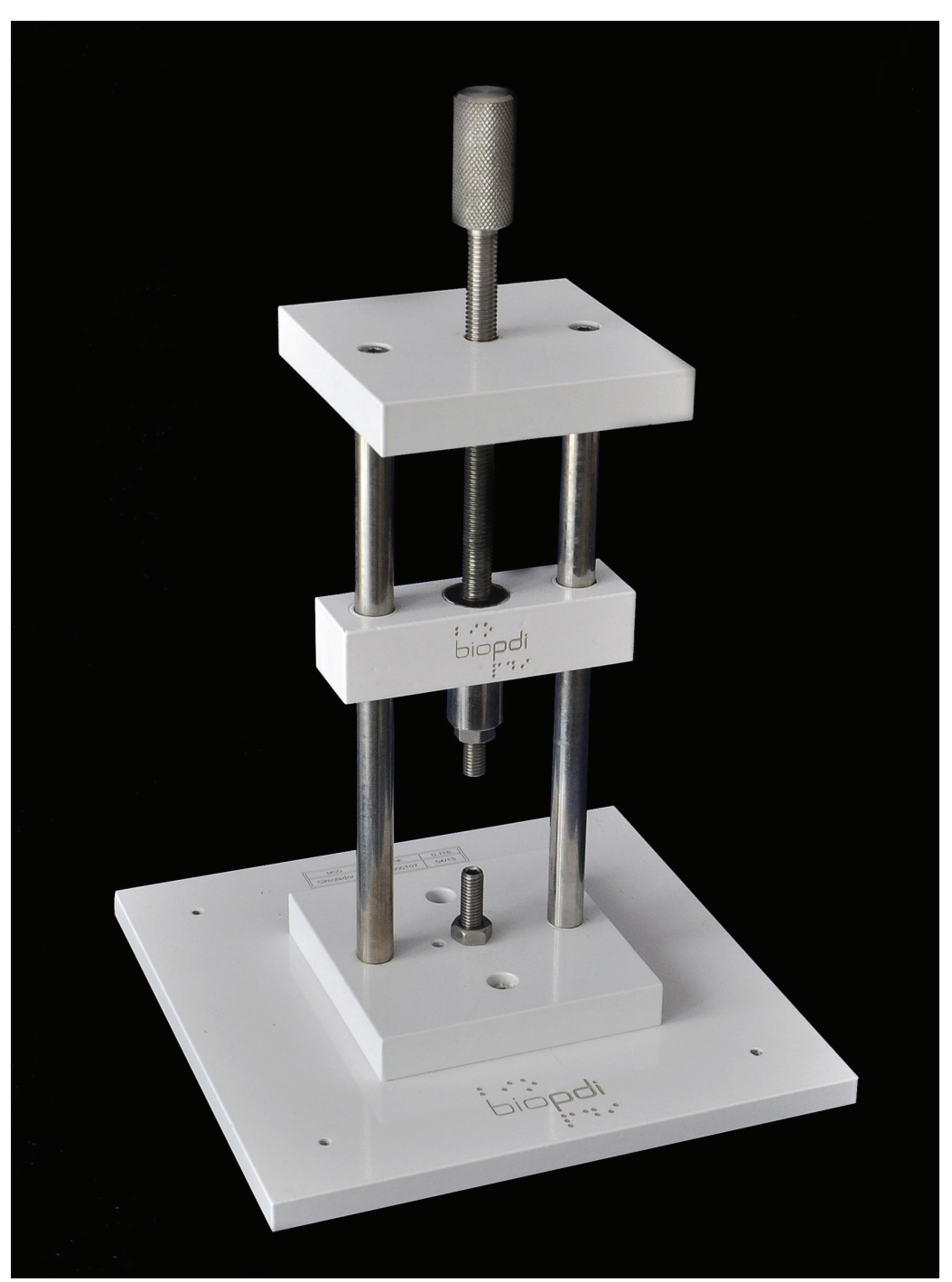

Figura 1 - Simulador Manual de Ensaios Mecânicos Odontológicos. 


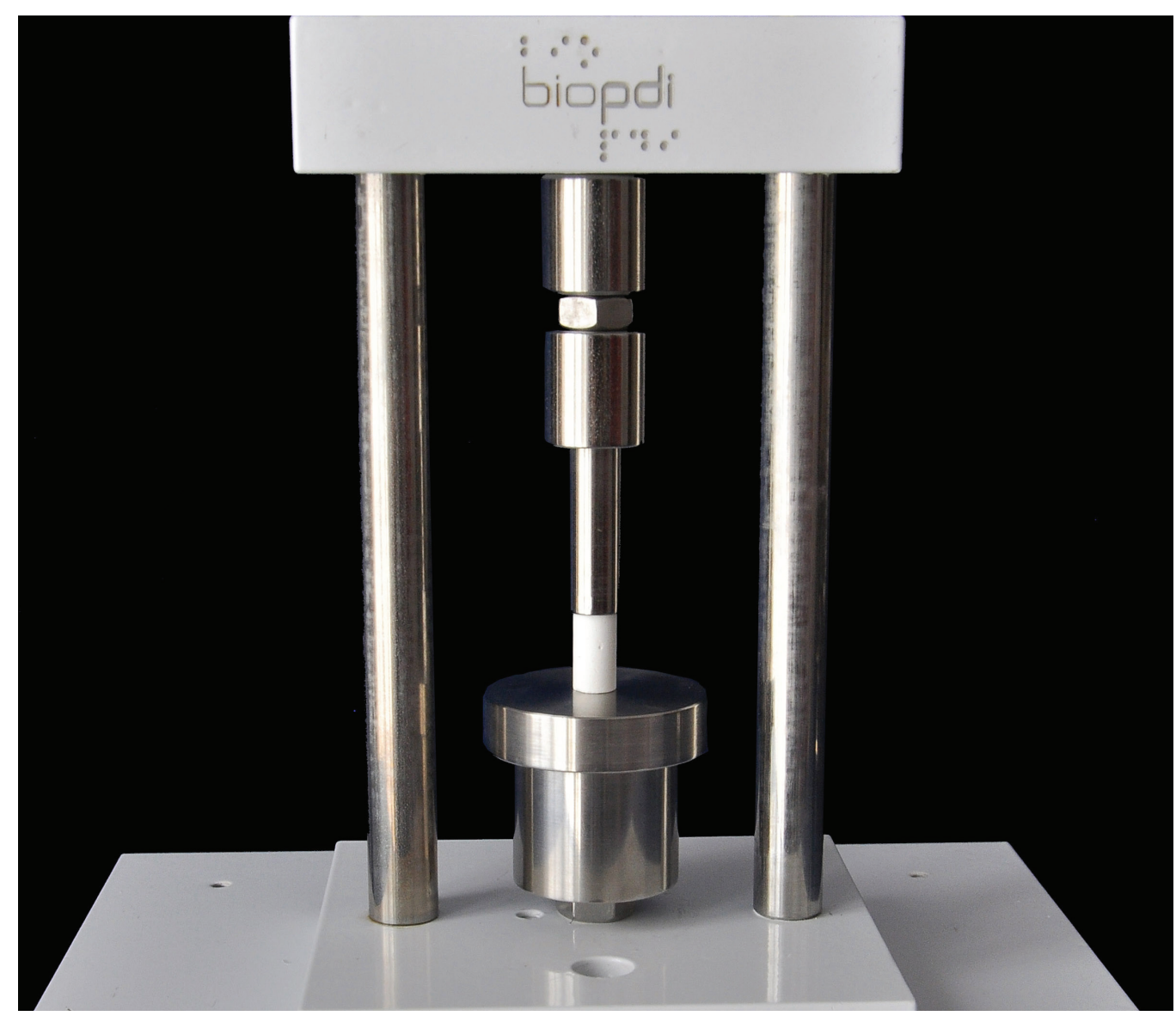

Figura 2 - Teste de compressão.

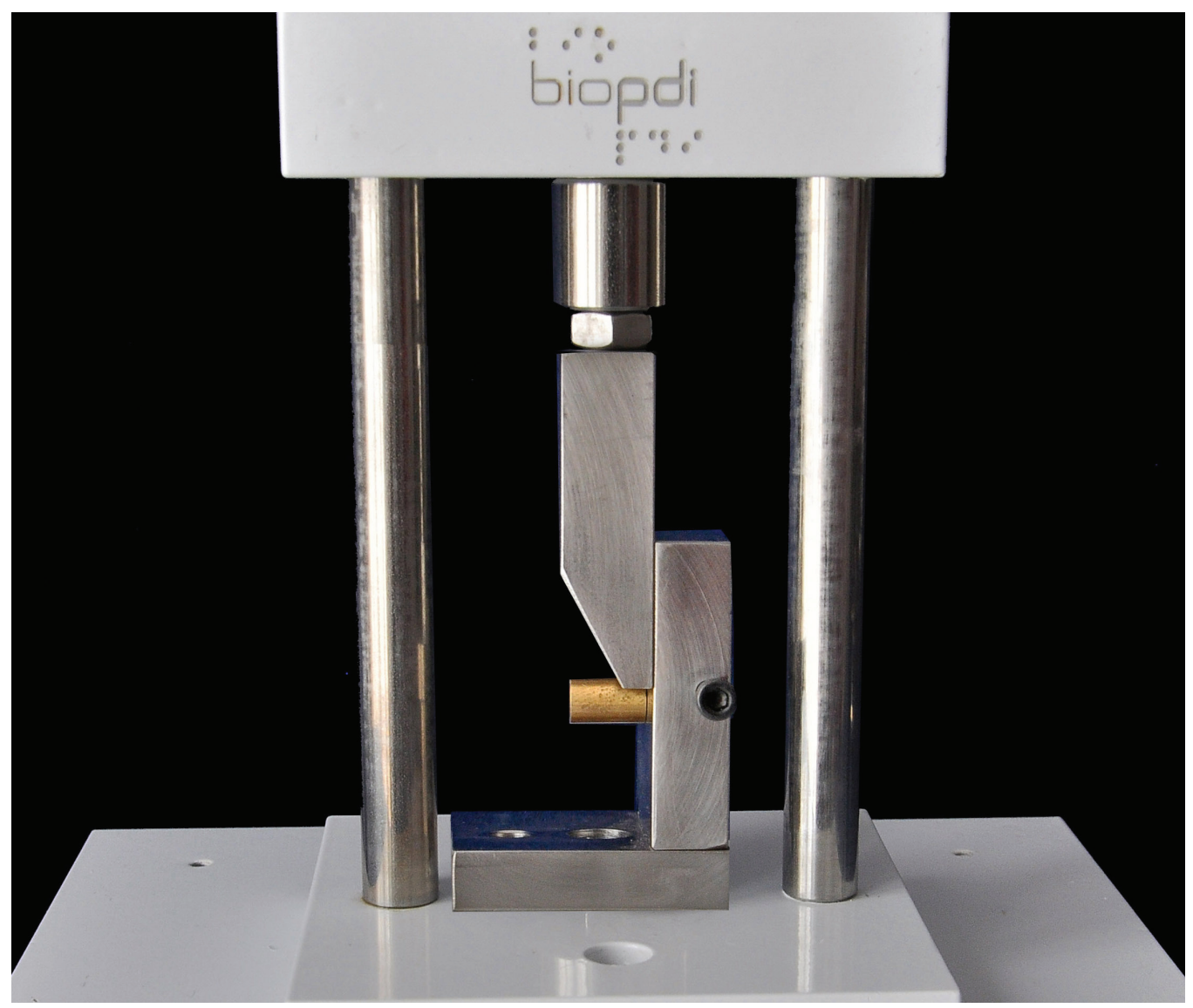

Figura 3 - Teste de cisalhamento. 


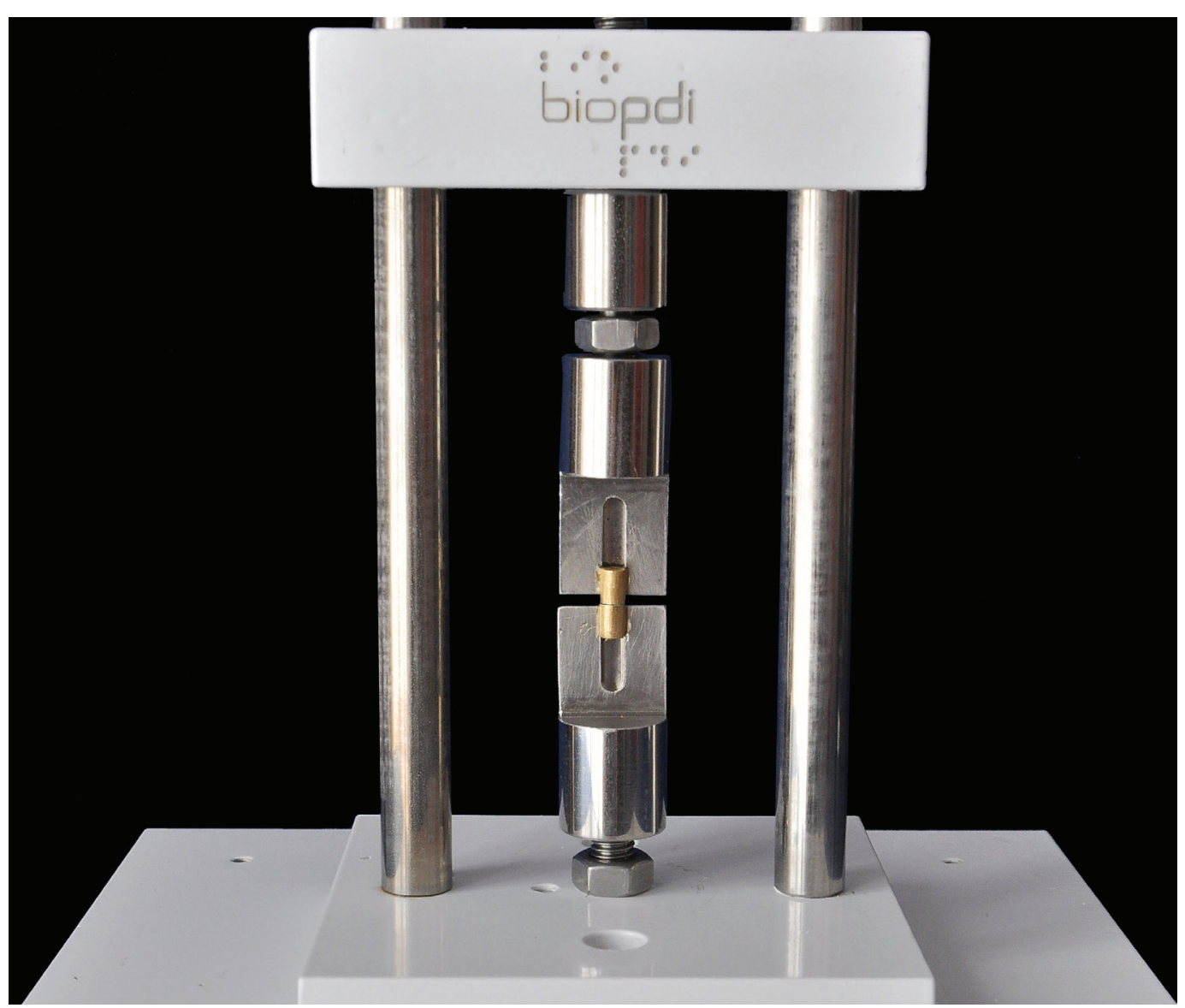

Figura 4 - Teste de tração.

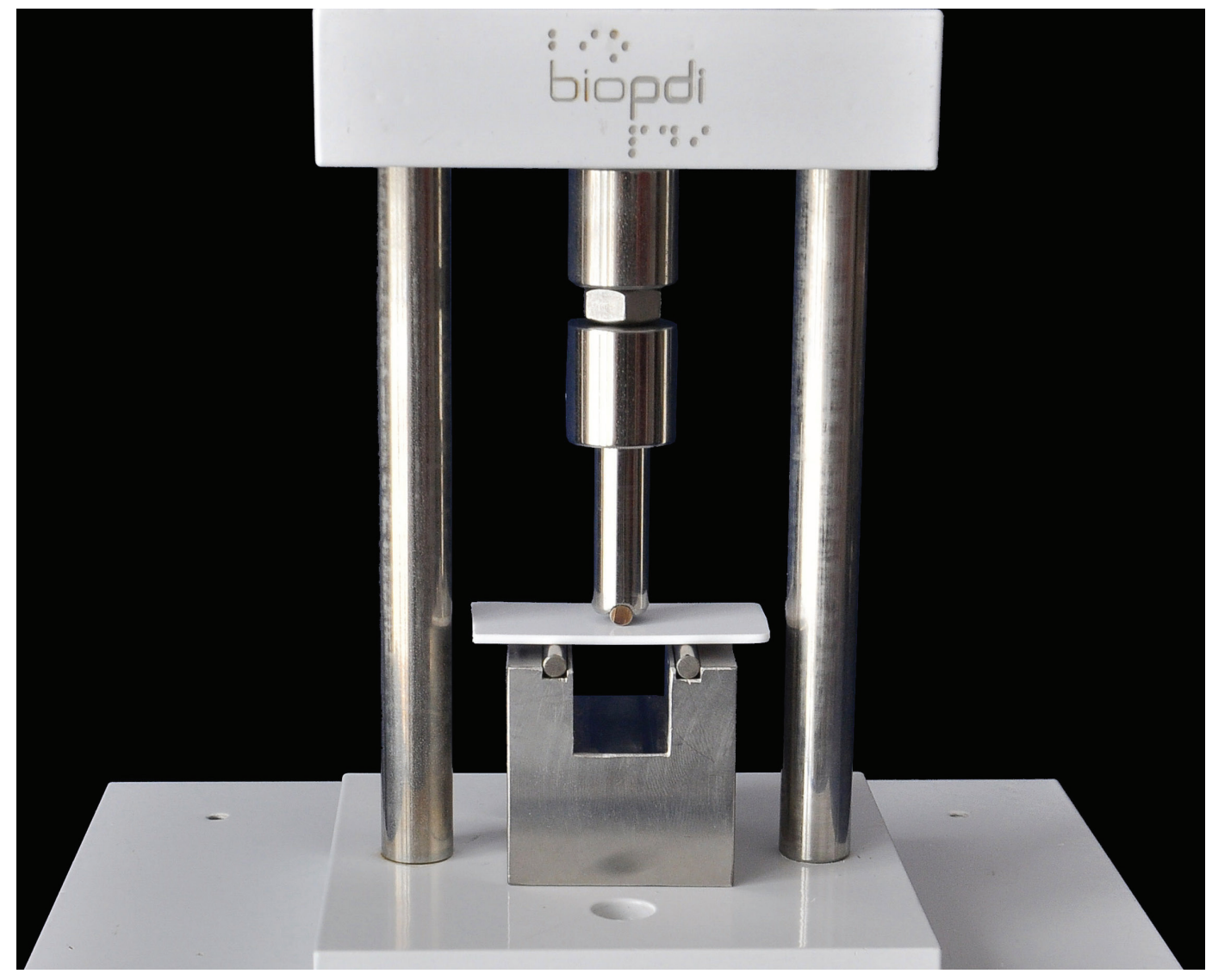

Figura 5 - Teste de flexão em três pontos. 


\begin{tabular}{|l|c|}
\hline Material & Resistência à Compressão (MPa) \\
\hline Amálgama & 388 \\
\hline Resina Composta & 277 \\
\hline Cimento de Fosfato de Zinco & 117 \\
\hline
\end{tabular}

Tabela 1 - Dados de resistência à compressão $(\mathrm{MPa})$ de três materiais odontológicos. Adaptado de CRAIG e POWERS (2004).

\section{Teste de cisalhamento}

Cisalhamento é o fenômeno de deformação ao qual um corpo está sujeito quando as forças que sobre ele agem provocam um deslocamento em planos diferentes. É um teste especialmente importante no estudo de interfaces entre dois materiais ou entre um material e uma estrutura dentária, como a interface da porcelana fusionada com o metal ou do cimento com o tecido dentário. Um método de se testar um material ao cisalhamento é aplicar uma carga axial para empurrar um material através de outro, ou seja, para que haja um deslizamento de uma superfície sobre a outra, como podemos observar na figura 3. Apesar de não ser um teste de cisalhamento "puro", pois existem outras forças atuando como a de compressão, é simples de realizar e tem sido muito utilizado, pois ilustra bem o conceito (CRAIG \& POWERS, 2004). A Tabela 2 descreve valores relacionados a teste de cisalhamento.

\section{Teste de tração}

É um teste utilizado, em especial, para a determinação de uma força de união entre dois corpos, em que os corpos são tracionados axialmente em sentidos opostos, como nas figuras 4 e 6 . A Figura 4 traz um corpo de prova de ímã, apenas para ilustrar o que seria a ruptura por forças de sentidos opostos. A Figura 6 é um esquema representativo das forças que tendem a alongar o objeto tracionado. Esse teste é particularmente utilizado para a determinação da força de união entre dois materiais como a resina e a dentina ou esmalte, cimentos e a efetividade de sistemas adesivos (CRAIG \& POWERS, 2004).

Além disso, o teste de tração é essencialmente importante para materiais friáveis, cuja resistência à tração é muito inferior à resistência à compressão, fato que pode levar o material à fratura quando em função mastigatória. Para esses casos é feito um teste em que um cilindro do material em questão é submetido a uma força compressiva no sentido do diâmetro desse cilindro, como na figura 7. Por se tratar de um material friável, as resultantes das forças no corpo do cilindro geram uma ou mais forças de tração em seu diâmetro, sendo esse tipo de teste chamado de teste de tração diametral.

\section{Teste de flexão em três pontos}

É um teste importante para a determinação da resistência transversal ou do módulo de ruptura de um determinado material odontológico, em que essa resistência ou módulo é resultado da interação entre suas outras forças: força de compressão e de tração, vistas na figura 8. O teste consiste no repouso de um corpo de prova em dois eixos fixos, sendo sujeito à compressão por um eixo axial móvel. Ao avanço desse eixo axial móvel, o corpo passa a ter intrinsecamente forças de compressão e de tracionamento, as quais podem levar à fratura do material ou a uma deformação. Esse teste é comumente utilizado em fios materiais protéticos para a confecção de próteses fixas com um ou mais elementos, para próteses parciais removíveis, para se determinarem a deformação de resinas e a resistência de cerâmicas quando esses materiais estiverem sujeitos às forças mastigatórias (CRAIG \& POWERS, 2004).

\section{Conclusão}

Com base no exposto, tal equipamento permite ao professor demonstrar ao aluno conceitos a priori essencialmente teóricos. Um número maior de alunos pode participar ativamente dos testes, visto que 


\begin{tabular}{|l|c|}
\hline Material & Resistência ao Cisalhamento (MPa) \\
\hline Amálgama & 188 \\
\hline Dentina & 138 \\
\hline Esmalte & 90 \\
\hline Porcelana & 111 \\
\hline
\end{tabular}

Tabela 2 - Dados de resistência ao cisalhamento $(\mathrm{MPa})$ de dois materiais odontológicos e dois tecidos dentários, o esmalte e a dentina. Adaptado de CRAIG e POWERS (2004).

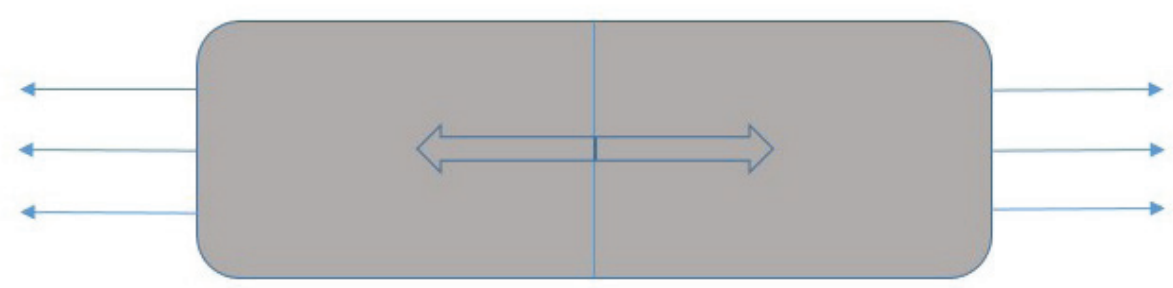

Figura 6 - Teste de tração, corpo tracionado axialmente em direções opostas.

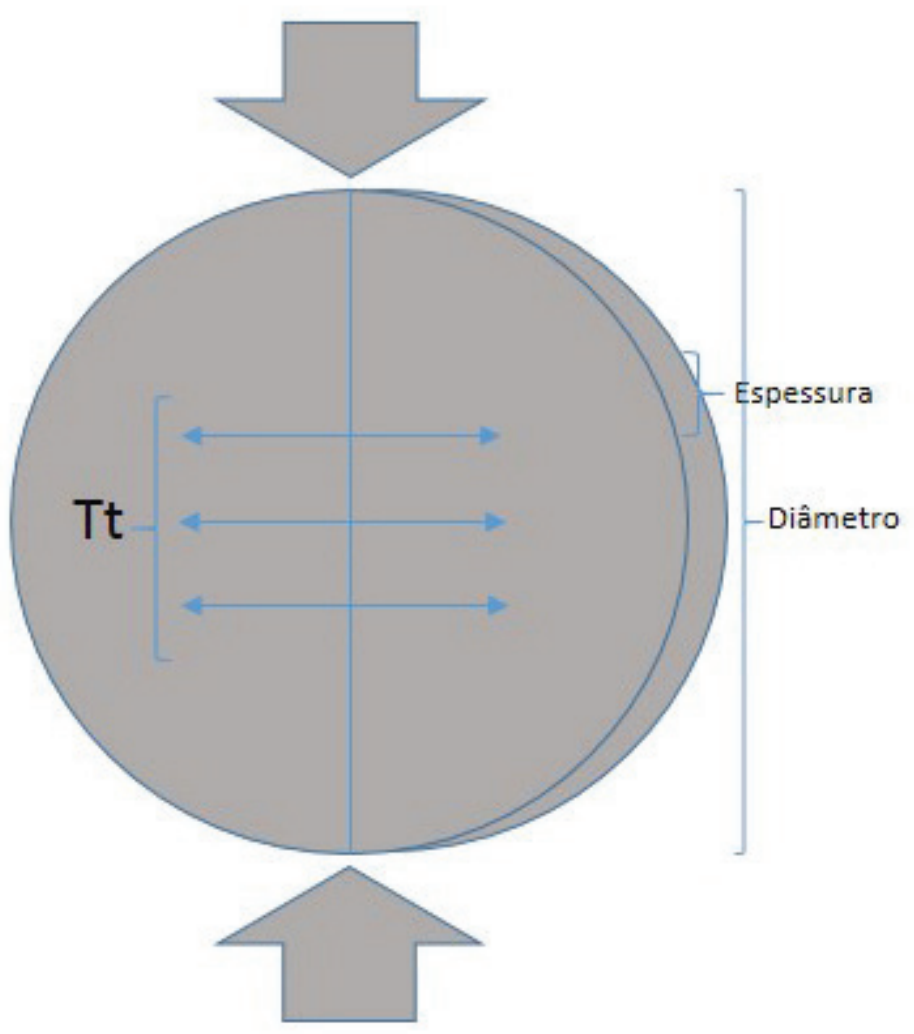

Figura 7 - Esquema representativo de um corpo de prova submetido ao teste de tração diametral para materiais friáveis. 


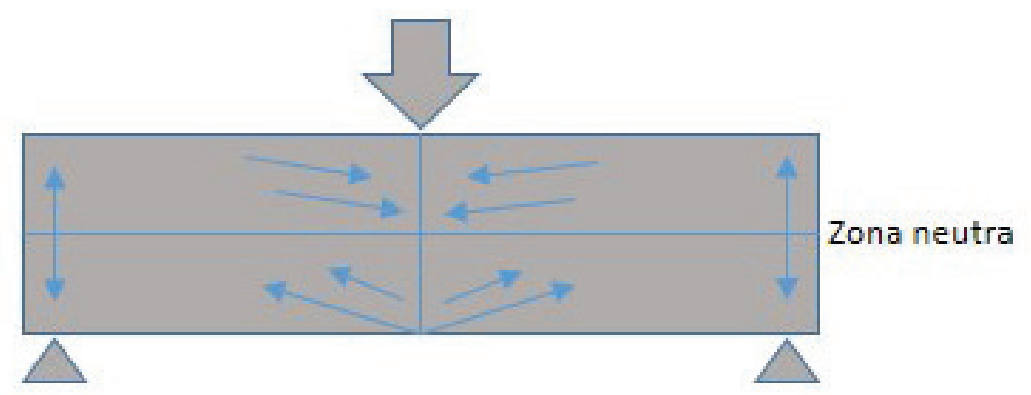

Figura 8 - Teste de flexão em três pontos exemplificando as forças de compressão e tração no corpo de prova. Note-se que, no ponto onde a força é aplicada, setas com indicação para dentro representam tensões de compressão; setas com indicação para fora representam tensões de tração.

a maquete se desloca ao laboratório de aulas práticas, e não o contrário, possibilitando otimização de tempo e tendo como resultado o retorno reflexivo em grupo e imediato sobre o conteúdo abordado. Além disso, os alunos conseguem assimilar melhor o conteúdo, uma vez que a visualização da direção dos testes mecânicos, assim como da direção das forças mastigatórias, pode clarear aspectos difíceis de serem entendidos por parte dos alunos. Tal procedimento também os estimula a pensar em questões do dia a dia da prática profissional, bem como os incentiva a darem a devida importância ao conteúdo apresentado pela visualização direta de sua aplicação profissional, tornando-se dessa maneira críticos, com conhecimento teórico embasado.

\section{Referências Bibliográficas}

BEGKER, Fernando. "O que é Construtivismo?".
Fundação para o Desenvolvimento da Educaşão: Série Ideias, São Paulo, n. 20, 1994. Disponível em: <http:// www.crmariocovas.sp.gov.br/pdf/ideias_20_p087093_c.pdP. Acessado em 7 jan. 2017.

GRAIG, R. G. \& POWERS, J. M. Materiais Dentários Restauradores. 11. ed. São Paulo: Editora Santos, 2004.

FELDER, Richard M. \& SILVERMAN, Linda Kreger. "Learning and Teaching Styles in Engineering Education". Fournal of Engineering Education, Whashington, n. 78, vol. 7, 1988, pp. 674-681. Disponível em: <http://www.ncsu.edu/ felder-public/Papers/LS-1988.pdf $>$. Acessado em 7 jan. 2017.

VIEIRA JUNIOR, Niltom \& COLVARA, Laurence Duarte. "A Prática Docente e Novos Recursos de Ensino para Estabilidade de Sistemas de Energia Elétrica". Congresso Brasileiro de Ensino de Engenharia. Curitiba, 2007. Disponível em: <http:// abenge.org.br/cobenges-anteriores/2007/2007-xxxv-cobenge-curitiba-pr $>$. Acessado em 7 jan. 2017.

Publicado em 31/03/2017. 